\title{
Upaya Meningkatkan Gerak Dasar Lempar Tangkap Melalui Permainan Frisbee
}

\author{
* Ramdani ${ }^{1}$ and Gano Sumaro ${ }^{1}$ \\ ${ }^{1}$ Program Studi Pendidikan Guru Sekolah Dasar Pendidikan Jasmani, \\ Fakultas Pendidikan Olahraga dan Kesehatan, Universitas Pendidikan Indonesia \\ email : ganosumarno@upi.edu
}

\begin{abstract}
Abstrak
Permsalahan penelitian ini adalah lemahnya pola gerak dasar lempar tangkap dalam pembelajaran pendidikan jasmani di sekolah dasar. Tujuan dari penelitian ini untuk mengungkapkan apakah penerapan pembelajaran frisbee games dapat meningkatkan pola gerak dasar lempar tangkap pada siswa sekolah dasar. Metode penelitian yang digunakan dalam penelitian ini adalah metode penelitian tindakan kelas (Classroom Action Research). Penelitian dilaksanakan pada siswa kelas V B di SDN Kartika Sejahtera 01 Kabupaten Bogor. Desain penelitian atau langkah-langkah penelitian yang dilakukan dalam penelitian tindakan kelas yaitu perencanaan atau planning, tindakan atau acting, pengamatan atau observing, dan refleksi atau reflecting. Instrumen yang digunakan dalam penelitian ini adalah lembar observasi, GPAI (Game Performance Assessment Instrument), catatan lapangan, dokumentasi, dan evaluasi. Pemecahan masalah dalam penelitian ini adalah implementasi pembelajaran frisbee games dapat meningkatkan pola gerak dasar lempar tangkap pada siswa sekolah dasar. Berdasarkan hasil penelitian yang dilaksanakan memperoleh hasil dari proses pembelajaran siswa pada pra observasi $50,31 \%$ dan siklus 1 tindakan 1 adalah 56,79\%, siklus 1 tindakan 2 adalah 59,41\%, siklus 2 tindakan 1 adalah $67,59 \%$, dan siklus 2 tindakan 2 adalah 75,15\%. Berdasarkan hasil pengolahan dan analisis data, kesimpulan dari hasil penelitian ini adalah penerapan frisbee games dapat meningkatkan dan memperbaiki pola gerak dasar lempar tangkap pada siswa sekolah dasar. Saran yang diberikan untuk meningkatkan hasil yang lebih optimal, dilakukan dengan siklus berikutnya.
\end{abstract}

Kata kunci: Pola Gerak Dasar, Lempar Tangkap, Permainan Frisbee.

*Ramdani adalah lulusan Program Studi PGSD Penjas, Departemen Pendidikan Olahraga, Fakultas Pendidikan Olahraga dan Kesehatan, Universitas Pendidikan Indonesia. 


\title{
Improving Basic Catching Movement Through Frisbee Games
}

\begin{abstract}
The problem of this research is the weakness of the basic movement pattern of throwing and catching in the learning of physical education in elementary school. The purpose of this study to reveal whether or not the application of learning frisbee games can improve the basic motor patterns of catching of the elementary school students. The research method used in this research is classroom action research. The subject of research was a group of students of grade V at SDN Kartika Sejahtera 01 Bogor Regency. The research design was following four steps progress; they are planning, acting, observing, and reflecting. The instruments used in this research are observation sheets, GPAI (Game Performance Assessment Instrument), field notes, documentation, and evaluation. The problem to be solved in this research is the implementation of frisbee games as learning tool to improve throwing and catching skills of the elementary school students. Based on the data analysis,can be concluded that the progress is obvious: on pre observation 50.31\%; on 1st cycle of action 1 is 56.79\%; on cycle 1 action 2 is $59.41 \%$, on cycle 2 action 1 is $67.59 \%$, and on cycle 2 action 2 is $75.15 \%$. It can be concluded that in general, this research has evidently prooved that the application of frisbee games can improve basic movement patterns of catching of the elementary school students.
\end{abstract}

Keyword: Basic Movement Patterns, throwing and catching skills, Frisbee Games

\section{PENDAHULUAN}

Pada pelaksanaan pembelajaran pendidikan jasmani terdapat berbagai macam materi yang diajarkan, salah satu diantaranya adalah pembelajaran gerak dasar lempar tangkap yang dikemas dalam permainan. Menoleh tentang sumber belajar atau materi ajar yang beragam yang dapat diajarkan kepada siswa, salah satu diantaranya adalah materi dalam pembelajaran pendidikan jasmani yaitu aktivitas pembelajaran invasi. Permainan invasi berupaya menguasai atau mempertahankan obyek permainan agar selalu ada pada regunya dengan jalan melakukan operanoperan (passing) atau membawa (dribbling), dan berusaha untuk 
mendapatkan obyek permainan dari regu lawan dengan jalan menghadang, atau merebutnya, untuk membuat atau mencegah terjadinya gol (Bahagia, 2010).

Dalam permainan invasi objek yang digunakan bisa bermacam-macam sesuai dengan kebutuhan ataupun ketersediaan alat. Objek yang digunakan dalam permainan invasi biasanya adalah bola, baik yang terbuat dari karet ataupun bola yang terbuat dari kertas sudah dimodifikasi. Alternatif objek yang bisa digunakan dalam permainan invasi adalah frisbee. permainan yang termasuk kedalam permainan invasi adalah permainan frisbee. Permainan frisbee adalah permainan lempar tangkap alat semacam piring (pipih) yang dibuat sedemikan rupa hingga dapat melayang menerobos udara ini dengan luncuran seimbang yang memperhitungkan prinsip aero dinamis dari alat itu Bahagia (2010). Pada hakekatnya permainan frisbee ini adalah masuk dalam kelompok permainan passing intercepting. Karena permainan ini bertujuan untuk membuahkan skor di daerah lawan dengan jalan dioperoperkan lewat keterampilan lemparan frisbee itu untuk diarahkan dan ditangkap oleh pemain satu regu, sedangkan pemain regu lawan berusaha unutk menghambat upaya untuk membuat skor.

Pada saat kondisi bermain, aktivitas lempar tangkap dalam frisbee games ini sangat menyenangkan, karena gerakan aerodinasmis dari frisbee terlihat menarik bagi siswa. Apabila siswa sudah mulai merasa tertarik maka siswa dapat bergerak aktif dan senang dalam mengikuti proses pembelajaran pendidikan jasmani. Sejalan dengan apa yang disampaikan oleh Kenedi (2016) menyatakan bahwa: "Efektivitas produk model permainan frisbee dapat diterima siswa untuk peningkatan aspek kognitif, 
psikomotor, dan afektif". Dengan mengimplementasikan frisbee games dalam pembelajaran pendidikan jasmani di sekolah diharapkan proses pembelajaran yang berjalan akan efektif dan optimal. Frisbee games mempunyai konsep melempar dan menangkap dengan teman sekelompoknya untuk mencetak angka sebanyak mungkin, hal ini bisa dijadikan solusi bagi guru pendidikan jasmani untuk mengembangkan sekaligus memberikan pengalaman baru berupa penggunaa media pembelajaran yang inovatif terutama di sekolah dasar untuk meningkatkan pola gerak dasar lempar tangkap pada siswa melalui permainan yang menarik dan menyenangkan.

Menurut hasil pengamatan dalam proses pembelajaran di kelas V Sekolah Dasar Negeri Kartika Sejahtera 01 pada pembelajaran pendidikan jasmani, materi yang diajarkan adalah pembelajaran permainan frisbee. Pada pelaksanaannya banyak menemui hambatan, misalnya dalam proses pembelajaran lempar tangkap siswa masih menemui kesulitan ketika melakukan lemparan dan tangkapan penyebabnya ialah siswa masih merasa takut, sehingga proses pembelajaran berjalan kurang efektif. Selain itu belum terbentuknya kordinasi tubuh yang baik pada saat melakukan pola gerak dasar melempar dan menangkap menjadi penyebab tidak berjalannya proses pembelajaran dengan baik, sehingga pembelajaran dianggap kurang menarik oleh siswa.

Dari permasalahan yang terjadi pada pembelajaran kebanyakan siswa mengeluh untuk tidak mau melakukan lempar tangkap frisbee, dikarenakan hasil dari lemparan tidak tepat sasaran, selain itu frisbee masih sulit dikendalikan pada saat melakukan lemparan disebabkan oleh 
kurangnya pemahaman mereka cara melempar serta menangkap frisbee. Tidak adanya variasi dalam melaksanakan lempar tangkap pun menjadi permasalahan ketika saat pembelajaran berlangsung sehingga jalanya pembelajaran cendrung membosankan dan siswa tidak antusia ketika mengikuti proses pembelajaran. Hal tersebut akan berdampak pada tujuan pembelajaran yang tidak efektif kurang maksimal yang diajarkan oleh guru di sekolah. Berdasarkan hasil uraian dan penjelasan latar belakang di atas, peneliti tertarik untuk melakukan penelitian tindakan kelas pada siswa kelas V SD Negeri Kartika Sejahtera 01 Kabupaten Bogor dengan judul, "Upaya Meningkatkan Pola Gerak Dasar Lempar Tangkap melalui Frisbee Games".

\section{METODE}

Metode penelitian yang penulis gunakan adalah meode Penelitian Tindakan Kelas (PTK) pada tingkat Sekolah Dasar, alasan penulis memilih PTK karena penulis sering menghadapi permasalahan dari objek yang terjadi pada saat kegiatan proses pembelajaran di kelas, tujuannya yaitu untuk memperbaiki kondisi praktek dalam proses pembelajaran.

\section{Subjek Penelitian}

Subjek penelitian dalam PTK ini adalah siswa kelas V B SDN Kartika Sejahtera 01 yang berjumlah 27 siswa dengan 13 siswa laki-laki dan 14 siswa perempuan. Peserta didik di Sekolah ini berasal dari latar belakang keluarga yang berbeda-beda, orang tua mereka berasal dari profesi yang berbeda-beda pula, ada yang berprofesi sebagai pedagang, guru, karyawan, aparat pemerintah, dan lain-lain. 


\section{Prosedur Penelitian}

Prosedur penelitian yang digunakan merujuk pada tahap penelitian yang dikemukakan oleh Menurut Kemmis dan McTaggart (dalam Asrori, 2014, hlm. 68) menyatakan: "Model penelitian tindakan kelas ini mengandung empat komponen, yaitu: a. Rencana (Planning), b. Tindakan (Action), c. Pengamatan (Observation), d. Refleksi (Reflection)".

\section{Instrumen}

Instrumen atau alat yang digunakan untuk mengumpulkan data dalam penelitian ini adalah Game Performance Assessment Instrument (GPAI) digunakan untuk mengukur atau menilai ketermapilan bermain siswa. Keterampilan bermain yang dimaksud memiliki 3 konstruk, yaitu (1) Keputusan yang diambil, (2) Melaksanakan keterampilan, (3) Memberi dukungan.

\section{HASIL DAN PEMBAHASAN}

Berikut ini adalah data hasil analisis tindakan melalui 2 siklus yang dilakukan dalam pelaksanaan penelitian tindakan kelas dalam Penerapan Fribee Games Untuk Meningkatkan gerak dasar lempar tangkap dalam pembelajaran permainan Frisbee. 
Tabel 1. Perolehan Nilai Presentase Pola Gera Dasar Lempar dan Tangkap Pada Pembelajaran Permainan Frisbee dari Setiap Tindakan

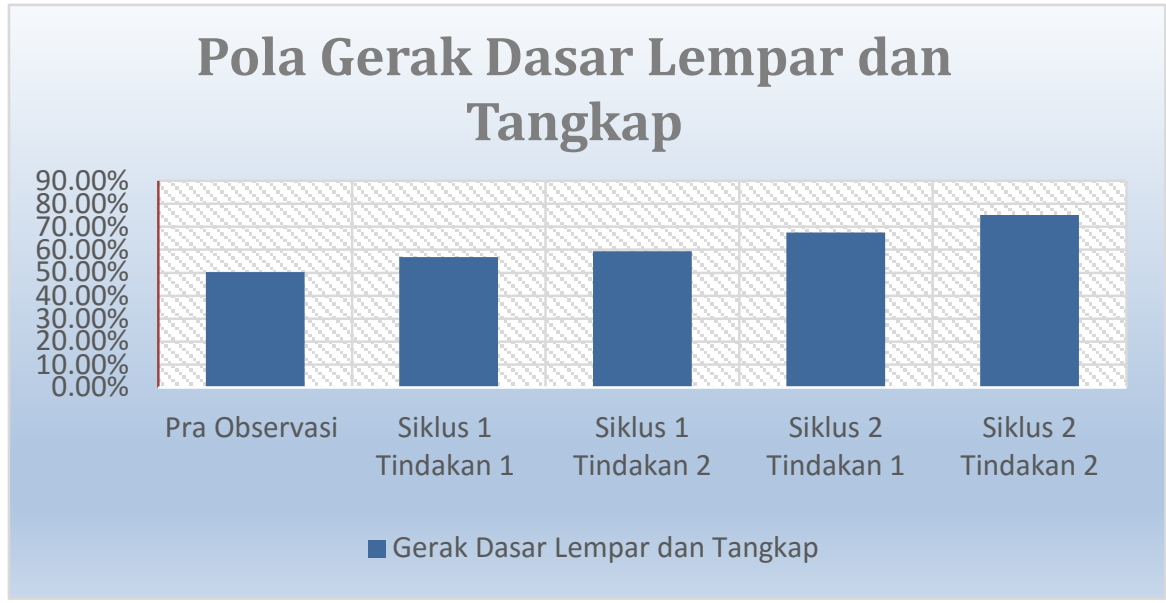

Berdasarkan hasil penelitian dari mulai observasi awal sampai dengan siklus ke dua tindakan ke dua, dapat diketahui bahwa penerapan pembelajaran frisbee games untuk meningkatkan gerak dasar lempar tangkap pada siswa kelas V B Sekolah Dasar Negeri Kartika Sejahtera 01 Kabupaten Bogor telah meningkat, dari 50,21\% menjadi 75,15\%. Setelah penulis bertindak sebagai peneliti dan guru (yang terjun langsung melakukan kegiatan mengajar) serta dibantu mitra peneliti (sebagai observer) dalam melakukan penelitian tindakan kelas dari awal sampai tahap akhir penelitian, diperoleh beberapa temuan sebagai berikut:

1. Dari hasil observasi awal diperoleh fakta bahwa:

a. Guru pendidikan jasmani kurang variatif dalam menyajikan materi pembelajaran sehingga antusias dalam permainan frisbee sangat kurang. 
b. Kurangnya upaya guru pendidikan jasmani dalam menggunakan media-media pendukung dalam pembelajaran dengan materi melempar dan menangkap pada permainan frisbee.

c. Guru pendidikan jasmani tidak dapat memperhatikan materi yang akan diajarkan pada saat proses pembelajaran permainan frisbee dengan memperhatikan karakteristik kemampuan siswa.

d. Dalam proses penyampaian materi guru pendidikan jasmani kurang menguasi kelas, terlihat ketika guru menjelaskan siswa kurang begitu mengerti apa yang disampaikan disebebkan oleh suara yang kurang lantang dan penjelasn yang terlalu cepat.

2. Dari hasil pelaksanaan tindakan kelas diperoleh fakta sebagai berikut:

a. Dalam proses pembelajaran pendidikan jasmani dengan permainan banyak sekali variasi permainan yang bisa diterapkan di sekolah salah satu diantaranya adalah permainan frisbee. Tidak melulu harus permainan yang sudah familiar yang ada dikalangan masyarakat seperti bola basket, bola voli, bola tangan (hand ball) dan banyak lagi permainan yang lainnya, bisa juga diterapkan permainan yang bisa juga meningkatkan pola gerak dasar lempar tangkap seperti permainan frisbee. Pada permainan frisbee tidak semuanya sekolah mempunyai fasilitas yang cukup untuk bermain frisbee, sulit menemukan sekolah yang mempunyai fasilitas lapangan yang luas untuk permainan frisbee. Untuk itu cara alternatif menerapkan permainan frisbee di sekolah tanpa peralatan yang sesuai dengan permainan yang sesungguhnya dapat dimodifikasi dengan permainan yang menyerupai permainan frisbee seperti frisbee games 
b. Penyajian materi atau tugas gerak harus diberikan kepada siswa dengan kesesuaian tingkat penguasaan siswa dalam menyelesaikan tugas ajar, perlu diperhatikan dalam pemilihan materi.

c. Pemberian dan penyajian tantangan melaksanakan tugas gerak sebaiknya harus berupa permainan agar anak merasa senang dan antusias dalam pembelajaran. Ini dilandasi asumsi dan kenyataan bahwa dunia anak adalah bermain. Seperti yang dijelaskan oleh Bahagia \& Mujianto. (2010, hlm. 155) bahwa: "Pada setiap aktivitas permainan, kegembiraan dan keterlibatan peserta didik dalam aktivitas bermain harus diutamakan. Ciptakan kemungkinan-kemungkinan yang dapat membuat permainan terlibat aktif dan gembira".

d. Memberikan peluang atau potensi untuk berkembangnya olahraga frisbee di indonesia.

Pengembangan permainan frisbee dapat dilakukan oleh semua kalang tidak terkecuali siswa, mahasiswa, guru, maupun dosen. Menurut Kenedi (2016, hlm. 218) menyatakan bahwa: "Pengembangan model permainan frisbee dapat dikembangkan pada siswa Sekolah Dasar (SD), siswa Sekolah Menengah Pertama (SMP) dan Mahasiswa disesuaikan dengan sarana dan prasarana yang ada di sekolah atau di Perguruan Tinggi disampaikan secara efektif dan kooperatif dalam permainan frisbee”. 


\section{KESIMPULAN}

Setelah penelitian dilakukan oleh peneliti dari mulai observasi awal hingga tindakan terakhir, yaitu siklus 2 tindakan 2, data awal adalah 50,31\% dan siklus 1 tindakan 1 adalah 56,79\%, siklus 1 tindakan 2 adalah $59,41 \%$, siklus 2 tindakan 1 adalah 67,59\%, dan siklus 2 tindakan 2 adalah $75,15 \%$. Berdasarkan hasil penelitian dari mulai observasi awal sampai dengan siklus ke dua tindakan ke dua, dapat diketahui bahwa penerapan pembelajaran frisbee games pada siswa kelas V B Sekolah Dasar Negeri Kartika Sejahtera 01 Kabupaten Bogor telah meningkat dari 50,21\% menjadi $75,15 \%$ peneliti menyimpulkan bahwa dengan penerapan pembelajaran frisbee games dapat mengeningkatkan pola gerak dasar lempar tangkap pada siswa kelas V B SDN Kartika Sejahtera 01 Kabupaten Bogor. 


\section{DAFTAR PUSTAKA}

Apriandi, A. (2016). Penerapan bola modifikasi untuk meningkatkan keterampilan pasing dalam permainan futsal. (Skripsi). Universitas Pendidikan Indonesia, Bandung.

Asrori, M. (2014). Penelitian tindakan kelas. Bandung: CV. Wacana Prima

Bahagia, Y. (2010). Permainan invasi. Bandung: Universitas Pendidikan Indonesia

Bahagia, Y. dan Mujianto, S. (2010). Fasilitas dan perlengkapan penjas. Bandung: FPOK Universitas Pendidikan Indonesia

Juliantine, T., Subroto, T., \& Yudiana, Y. (2012). Belajar dan pembelajaran pendidikan jasmani. Bandung: Universitas Pendidikan Indonesia

Kenedi, D. (2016).

Pengembangan Model Permainan Frisbee Sebagai Alternatif Pembelajaran Pendidikan Jasmani Olahraga Dan Kesehatan Siswa SMA. Jurnal Pendidikan. Seminar Nasional Pendidikan Serentak Se Indonesia Tahun 2016 hal. 224-225

Mahendra, A. (2007). Teori belajar mengajar motorik, Modul. Bandung: Universitas Pendidikan Indonesia

Mahendra, Agus. (2015). Filsafat Pendidikan Jasmani: Dasar-dasar Pembelajaran Penjas di Sekolah Dasar. Bandung: CV. Bintang WarliArtika.

Mahendra, Agus. (2017). Model Pendidikan Gerak, Implementasi Pendidikan Jasmani di Sekolah Dasar. Modul. Bandung: FPOKUPI.

Subroto, T. dkk. (2014). Penulisan penelitian tindakan kelas dalam pendidikan jasmani, olahraga, dan kesehatan. Bandung: Universitas Pendidikan Indonesia

Sugiyono. (2010). Metode penelitian pendidikan. Bandung: CV. Alfabeta

Undang-Undang Republik Indonesia Nomor 20 Tahun 2003 Tentang Sistem Pendidikan Nasional 